\title{
$\mathrm{TiFe}$ 공정합금의 미소합금 첨가에 따른 미세구조 변화 및 기계적 물성
}

이찬호 · 조재혁 · 문상철 · 김정태 · 여은진 · 김기범 ${ }^{\dagger}$

세종대학교 나노신소재공학과

\section{Influence of Minor Element on Microstructure and Mechanical Properties of TiFe Ultrafine Eutectic Alloys}

\author{
Chan Ho Lee, Jae Hyuk Jo, Sang Chul Mun, Jung Tae Kim, Eun Jin Yeo and Ki Buem Kim ${ }^{\dagger}$ \\ Department of Advanced Materials Engineering, Sejong University, 98 Gunja-dong, \\ Gwangjin-gu, Seoul 143-747, Korea
}

(2012년 10월 4일 접수 : 2012년 10월 23일 최종수정 : 2012년 10월 24일 채택)

\begin{abstract}
Recently, ultrafine grained (ufg, typically $100>d>500 \mathrm{~nm}$ ) Ti-Fe eutectic materials have been highlighted due to their extraordinarily high strength and good abrasion resistance compared to conventional coarse grained (cg, d $>1 \mu \mathrm{m})$ materials. However, these materials exhibit limited plastic strain and toughness during room temperature deformation due to highly localized shear strain. Several approaches have been extensively studied to overcome such drawbacks, such as the addition of minor elements ( $\mathrm{Sn}, \mathrm{Nb}, \mathrm{Co}$, etc.). In this paper, we have investigated the influence of the addition of $\mathrm{Gd}$ and $\mathrm{Y}$ contents (0.3-1.0 at.\%) into the binary Ti-Fe eutectic alloy. Gd and Y are chosen due to their immiscibility with Ti. Microstructural investigation reveals that the Gd phase forms in the eutectic matrix and the Gd phase size increases with increasing Gd content. The improvement of the mechanical properties is possibly correlated to the precipitation hardening. On the other hand, in the case of Ti-Fe-Y alloys, with increasing Y contents, primary phases form and lamellar spacing increases compared to the case of the eutectic alloy. Investigation of the mechanical properties reveals that the plasticity of the Ti-Fe$\mathrm{Y}$ alloys is gradually improved, without a reduction of strength. These results suggest that the enhancement of the mechanical properties is closely related to the formation of the primary phase.
\end{abstract}

Key words Ti, Fe, eutectic, mechanical property, alloy design, immiscible.

\section{1. 서 론}

최근 재료과학 분야에서 극미세 공정조직을 가지는 구 조용 합금의 개발이 활발히 진행되고 있다. 이런 극미 세 공정합금은 우수한 기계적, 물리적 특성을 가지며 조 대한 결정립 재료와 비교하여 높은 강도값과 우수한 마 모 저항성을 나타낸다. ${ }^{1-3)}$ 하지만, 이런 극미세 공정조직 을 가지는 재료는 상온에서 제한적인 소성 변형능을 보 일 뿐 아니라 항복 이후 급작스러운 파괴가 발생하며, 고비용 공정 과정이 요구되어진다는 점에서 산업화에 어 려움을 겪고 있다. 이러한 단점을 극복하기 위하여, 주 조를 이용하여 간단한 방법으로 마이크론 크기를 가지 는 제 이상과 나노구조 기지로 이루어진 불균일 미세조 직을 형성하는 방법 등이 활발히 연구되고 있다. ${ }^{4-7)}$ 불 균일 미세조직은 공정반응을 이용하여 극미세 층상조직

Corresponding author

E-Mail : kbkim@sejong.ac.kr (K. B. Kim)
을 쉽게 얻을 수 있고, 간단히 조성을 변화시킴으로써 마이크론 크기의 초정상 또는 수지상의 분율과 크기를 제어하여 분균일 미세조직을 형성할 수 있다. 공정반응 을 이용하여 이러한 불균일 미세조직을 가지는 재료를 극미세 공정-수지상 복합체라 칭한다. 극미세 공정-수지 상 복합체에서 극미세 공정조직은 합금의 기계적 강도 향 상에 중요한 역할을 하며, 마이크론 크기의 초정상은 합 금의 소성 변형능 향상에 주도적으로 작용한다. 그 결과 새로운 고강도 고인성 나노구조재료의 개발 가능성이 높 아 극미세 공정-수지상 복합체에 대해 활발한 연구가 진 행되고 있지만, 마이크론 크기의 초정상의 분율이 증가 함에 따라 연성이 증가하는 반면, 강도는 큰 폭으로 감 소한다는 치명적인 단점이 나타났다. 이러한 단점을 극 복하고 고강도를 유지하며 연성을 증가 시키기 위해 여 러 가지 해결책이 제시 되었다. 첫 번째로 공정합금의 eutectic colony 형상 변화 및 크기 불균일성(length-scale heterogeneity)을 유도한 고강도 고인성 공정합금 이다. ${ }^{8-10)}$ 두 번째 방법으로는 서로 다른 두 개의 공정조직, 즉 양 
극화 공정조직(bimodal eutectic structure)을 형성하여 우 수한 기계적 물성이 나타나는 것이 연구 되었다. ${ }^{11)}$ 일반 적으로 나노/극미세 결정립 소재의 경우 높은 전단 응 력에 의해 형성된 전단 띠에서 국부적인 소성 유동을 가 지는 불균일 소성 변형이 발생되어지고, 이런 높은 전 단 에너지를 갖는 전단 띠의 형성과 순간적인 전파로 급 격한 파괴가 발생되어진다고 알려져 있다. 그러나 양극 화 공정 조직 복합체의 경우, 이종 공정조직 간의 계면 이 다수의 전단 띠의 형성을 유도할 뿐 아니라, 미세조 직적 불균일성이 전단띠의 전파를 효과적으로 방해하여 결과적으로 소성변형능을 크게 향상시킬 수 있다고 연 구되어 졌다. ${ }^{21}$ 하지만 이런 연구는 이미 많이 진행되어 왔으며 신 개념의 합금개발에 대한 연구가 필요하다. 본 연구에서는 새로운 패러다임의 재료 개발을 이루고자 $\mathrm{Ti}_{70.5} \mathrm{Fe}_{29.5}$ 의 공정합금에 $\mathrm{Ti}$ 과 열역학적으로 액상 분리현 상을 나타내는 $\mathrm{Gd}$ 과 $\mathrm{Y}$ 을 소량 첨가함으로써 미소합금 화를 통하여 기존의 높은 강도를 가지는 $\mathrm{TiFe}$ 공정합금 에 연성을 증가시켜 고강도 고연성의 합금을 제작하고 자 하였다.

\section{2. 실험 방법}

\section{1 시편 제조 방법}

$\mathrm{TiFe}$ 공정합금에 $\mathrm{Gd}, \mathrm{Y}$ 이 소량 첨가된 모합금을 제 조하기 위해서, $99.9 \%$ 이상의 고순도의 원소들을 고순도 아르곤 가스 분위기 하에서 Arc 용해법을 이용하여 제 조하였다. 또한 합금의 편석 방지 및 균일한 합금화를 위 해 3회 이상 시편을 반전 시키며 용해하였다. 이렇게 준 비된 모합금을 흡입주조(arc suction)법을 이용하여 지름 $3 \mathrm{~mm}$ 그리고 높이 $50 \mathrm{~mm}$ 원통형 시편을 제조하였다.

\section{$2.2 \mathrm{X}$-선 회절 분석}

$\mathrm{Arc}$ 흡입법으로 제작되어진 $\mathrm{TiFeGd}, \mathrm{TiFeY}$ 합금의 상 분석을 위하여 X-선 회절 분석 장비(Rigaku Model: D/ $\mathrm{MAX}-2500 / \mathrm{PC}$ )를 이용하여 조사하였다. 본 연구의 $\mathrm{X}$ 선 회절 분석은 파장 $\lambda=1.5406 \AA$ 의 $\mathrm{CuK \alpha} 1$ target을 사 용하였고, 튜브 전압은 $40 \mathrm{kV}$, 전류는 $100 \mathrm{~mA}$ 의 조건으 로 분석을 행하였다. X-선 회절 스펙트럼은 연속주사의 방법으로 $20^{\circ} \sim 80^{\circ}$ 의 범위에서 $4 \% \mathrm{~min}$ 의 속도로 얻어졌다.

\section{3 주사 전자 현미경 분석: SEM(Scanning Electron Microscopy)}

$\mathrm{Arc}$ 흡입법으로 제작된 $\mathrm{TiFe}$-계 합금의 생성상의 형상 과 크기를 측정하기 위하여 주사전자 현미경(SEM: JEOL JSM-6390, FE-SEM: Hitachi S-4700)을 이용하였다. 시 편을 조사할 경우, 시편을 에칭하지 않고 관찰하는 back scattered electron를 이용하여 형성된 상의 명암차를 보 고 미세조직을 관찰하였으며, 이 때 주사 전자 현미경 은 가속전압은 $20 ~ 25 \mathrm{kV}$, spot size는 60 의 조건으로 설 정하였다.

\section{4 기계적 특성 평가}

제조된 합금의 시편의 기계적 특성을 평가하기 위하여 만능시험기(Universal Testing Machine)를 이용하여 압축 강도를 측정하였다. 압축강도 측정은 상온에서 등축압축 응력으로 시험하였으며 일정한 변형속도(strain rate $=1$ $\times 10^{-3} / \mathrm{s}$ )의 조건에서 수행되었다. 압축시험을 위한 시편 은 직경 $3 \mathrm{~mm}$, 높이 $6 \mathrm{~mm}$ 의 봉상시편으로 준비하였으 며 정확한 기계적 물성을 평가하기 위해 같은 조건의 합 금에서 최소 5 회 이상 압축 시험을 시행하였다.

\section{3. 결과 및 고찰}

Fig. 1은 $\mathrm{Arc}$ 흡입법으로 제작한 $\left(\mathrm{Ti}_{70.5} \mathrm{Fe}_{29.5}\right)_{100-\mathrm{X}} \mathrm{Gd}_{\mathrm{X}}$ 와 $\left(\mathrm{Ti}_{70.5} \mathrm{Fe}_{29.5}\right)_{100-\mathrm{X}} \mathrm{Y}_{\mathrm{X}}(\mathrm{X}=0.3 \sim 1.0$ at.\%)의 $\mathrm{X}$-선 회절 분 석 결과를 나타내고 있다. JCPDS 와 대조하여 수행한 상 분석을 통해 주요 회절픽은 bcc $\beta-\mathrm{Ti}$ (A2) 고용체, TiFe (B2) 금속간 화합물의 혼합으로 확인되었고, $\mathrm{Gd}$ 과 $\mathrm{Y}$ 의 함량이 증가함에도 불구하고 $\mathrm{Gd}$ 과 $\mathrm{Y}$ 에 관련된 회절 픽은 나타나지 않았다. Fig. 2((a)-(f))는 TiFeGd, TiFeY의 미세조직 사진을 나타내고 있다. Fig. 2((a)-(c))는 $\left(\mathrm{Ti}_{70.5}\right.$ $\left.\mathrm{Fe}_{29.5}\right)_{100-\mathrm{X}} \mathrm{Gd}_{\mathrm{X}}(\mathrm{X}=0.3 \sim 1.0$ at.\%) 합금의 back scattered electron(BSE) 사진으로 어두운 명암을 가지는 $\beta-\mathrm{Ti}$ 와

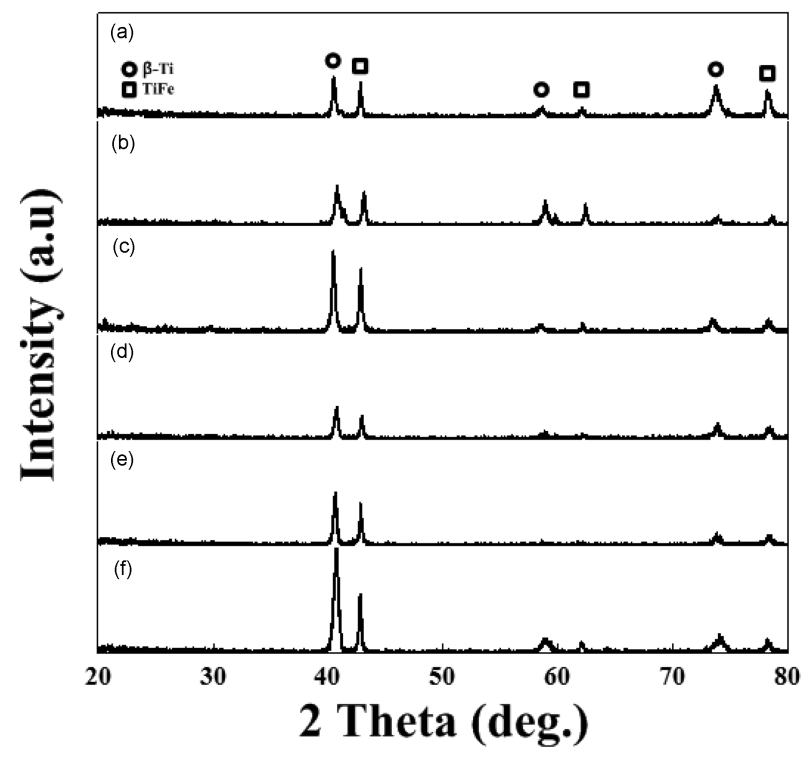

Fig. 1. $\mathrm{XRD}$ phase analysis of the $\left(\mathrm{Ti}_{70.5} \mathrm{Fe}_{29.5}\right)_{100-\mathrm{X}} \mathrm{Gd}_{\mathrm{X}}$ and $\left(\mathrm{Ti}_{70.5}{ }^{-}\right.$ $\left.\mathrm{Fe}_{29.5}\right)_{100-\mathrm{X}} \mathrm{Y}_{\mathrm{X}}$ alloys $\mathrm{X}=0.3$ at.\% 1.0 at.\%; (a) $\left(\mathrm{Ti}_{70.5} \mathrm{Fe}_{29.5}\right)_{99.7} \mathrm{Gd}_{0.3}$, (b) $\left(\mathrm{Ti}_{70.5} \mathrm{Fe}_{29.5}\right)_{99.5} \mathrm{Gd}_{0.5}$, (c) $\left(\mathrm{Ti}_{70.5} \mathrm{Fe}_{29.5}\right)_{99.0} \mathrm{Gd}_{1.0}$, (d) $\left(\mathrm{Ti}_{70.5} \mathrm{Fe}_{29.5}\right)_{99.7} \mathrm{Y}_{0.3}$, (e) $\left(\mathrm{Ti}_{70.5} \mathrm{Fe}_{29.5}\right)_{99.5} \mathrm{Y}_{0.5}$ and (f) $\left(\mathrm{Ti}_{70.5} \mathrm{Fe}_{29.5}\right)_{99.0} \mathrm{Y}_{1.0}$. 

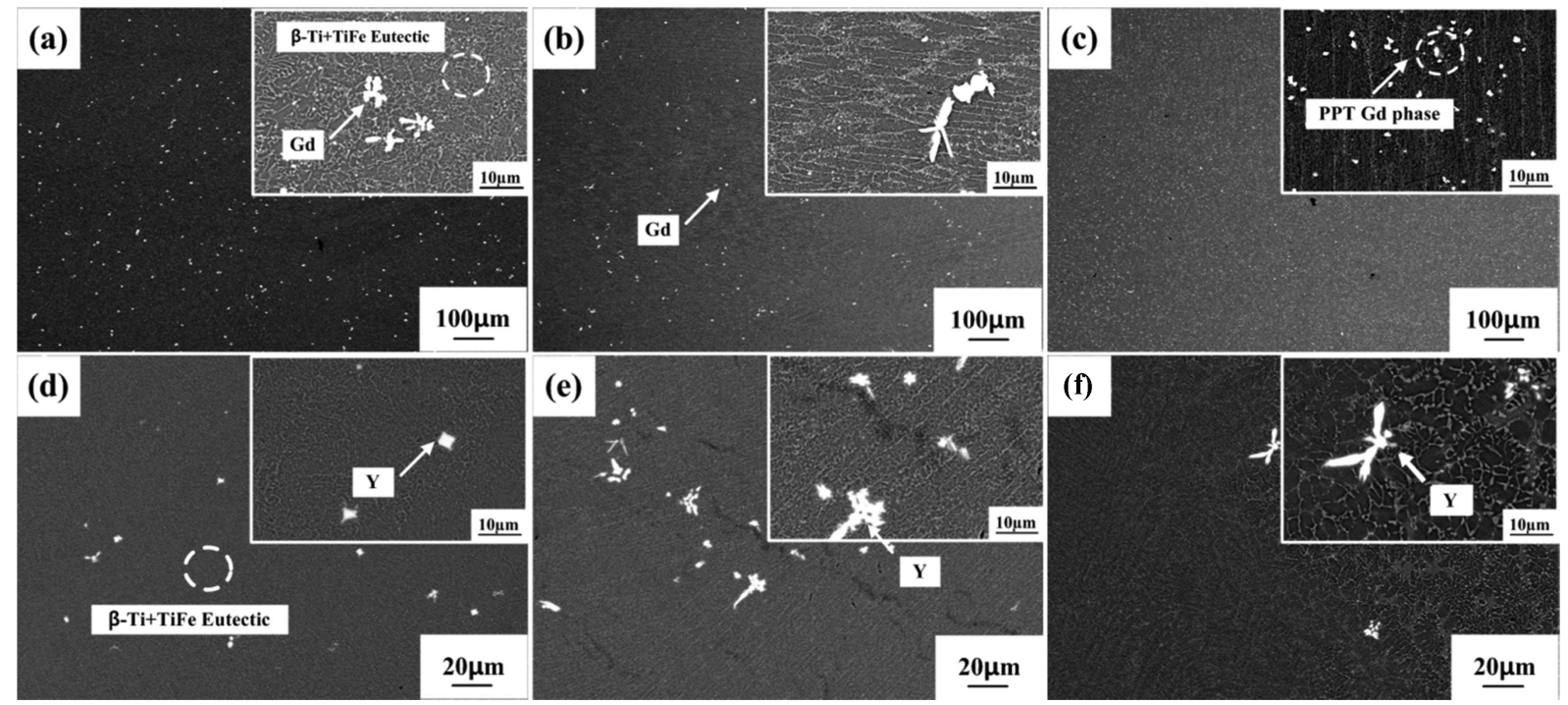

Fig. 2. $\mathrm{SEM}$ micrographs of the $\left(\mathrm{Ti}_{70.5} \mathrm{Fe}_{29.5}\right)_{100-\mathrm{X}} \mathrm{Gd}_{\mathrm{X}}$ and $\left(\mathrm{Ti}_{70.5} \mathrm{Fe}_{29.5}\right)_{100-\mathrm{X}} \mathrm{Y}_{\mathrm{X}}$ ultrafine eutectic composites $\mathrm{X}=0.3$ at.\% 1.0 at.\%: (a) Gd 0.3 at.\%, (b) Gd 0.5 at.\%, (c) Gd 1.0 at.\%, (d) Y 0.3 at.\%, (e) Y 0.5 at.\% and (f) Y 1.0 at.\%.

회색의 명암을 가지는 $\mathrm{TiFe}$ 로 이루어진 극미세 공정기지 에 밝은 명암으로 나타나는 마이크론 크기의 $\mathrm{Gd}$ 상이 분 포되어 있음을 알 수 있다. 공정기지의 lamellar spacing 은 3-5 $\mu \mathrm{m}$ 이며 $\mathrm{Gd}$ 의 첨가량이 증가함에 따라 $1-3 \mu \mathrm{m}$ 로 변화함을 볼 수 있었다. 또한 $\mathrm{Gd}$ 의 상의 크기와 분 포가 첨가량의 증가에 따라 그 크기가 감소하며 시편 전 체에 균일하게 형성됨을 볼 수 있었다. 그와 더불어 공 정기지의 colony의 크기가 줄어들며 일정한 방향성을 나 타내고 있다. $\mathrm{Gd}$ 상의 부피분율은 첨가량이 0.3 at.\% 일 때 $1.11 \%$ 였으며, 1.0 at.\% 일 때는 $2.19 \%$ 로 증가함을 알 수 있었다. 따라서 $\mathrm{Gd}$ 의 양이 아주 소량임에도 불구하고 첨가량의 증가에 따라 $\mathrm{Gd}$ 상이 균일하게 분포 되는 것으 로 보아 응고 시 $\mathrm{Ti}$ 과 액상분리현상을 가지는 $\mathrm{Gd}$ 이 $\beta$ $\mathrm{Ti}$ 상에 고용되지 않고 $\mathrm{PPT}$ 상으로 석출되는 것을 볼 수 있었다. Ti과 $\mathrm{Fe}$ 와의 자세한 혼합열 수치는 Table 1에 정 리되어 있다. 반면, $\left(\mathrm{Ti}_{70.5} \mathrm{Fe}_{29.5}\right)_{100-\mathrm{X}} \mathrm{Y}_{\mathrm{X}}(\mathrm{X}=0.3 \sim 1.0$ at.\%) 합금의 경우 Fig. 2((d)-(f))는 $\mathrm{Gd}$ 이 첨가되었을 때와 달 리 $\mathrm{Y}$ 상이 수지상 형태로 나타났으며, $\mathrm{Y}$ 의 첨가량이 증 가함에 따라 수지상의 크기와 모양이 조대해짐과 동시 에 그 수가 많이 줄어듬을 알 수 있었다. $\mathrm{Y}$ 의 첨가량 이 1.0 at.\%일 때는 $\beta$-Ti 와 $\mathrm{TiFe}$ 로 이루어진 공정기지의 length scale이 5-10 $\mu \mathrm{m}$ 로 증가하는 구간이 국부적으로 발 생하여 구조적 불균일성이 일어남을 알 수 있었다. 또한 수지상의 크기는 Y의 함량이 0.3 at.\% 일 때는 $3 \sim 6 \mu \mathrm{m}$

Table 1. The value of heat of mixing with $\mathrm{Gd}$ and $\mathrm{Y}$.

\begin{tabular}{ccc}
\hline$\Delta$ Hmix & $\mathrm{Ti}(\mathrm{KJ} / \mathrm{mole}$ of atom $)$ & $\mathrm{FE}(\mathrm{KJ} / \mathrm{mole}$ of atom $)$ \\
\hline $\mathrm{Gd}$ & 15 & -1 \\
$\mathrm{Y}$ & 15 & -1 \\
\hline
\end{tabular}

였으며 첨가량의 증가함에 따라 1.0 at.\%일 때는 $10 \sim 15$ $\mu \mathrm{m}$ 로 커지는 것을 확인할 수 있었다. 이는 응고 시 $\mathrm{Y}$ 의 초정상이 $\mathrm{Ti}$ 와는 섞이지 않고 $\mathrm{Fe}$ 와 고용도를 가지면 서 공정기지의 $\beta-\mathrm{Ti}$ 상의 length scale에 큰 영향을 준 것 으로 사료되어 진다. 따라서 $\mathrm{Y}$ 의 첨가에 의한 초정상의 생성은 공정기지의 불균일도에 중요한 요인으로 작용되어 기계적 물성의 변화에 결정적인 역할을 할 것으로 보인 다. 따라서 액상분리현상을 가지는 $\mathrm{Gd}$ 과 $\mathrm{Yd}$ 의 첨가를 통 한 미소합금화는 응고시 $\mathrm{Gd}$ 과 $\mathrm{Y}$ 의 원소가 높은 고용도 를 가지는 $\beta$-Ti 상에 고용되어 있다가 saturation되어 주 시상 과 석출상 형성에 주요한 영항을 준 것으로 사료 되어진다.

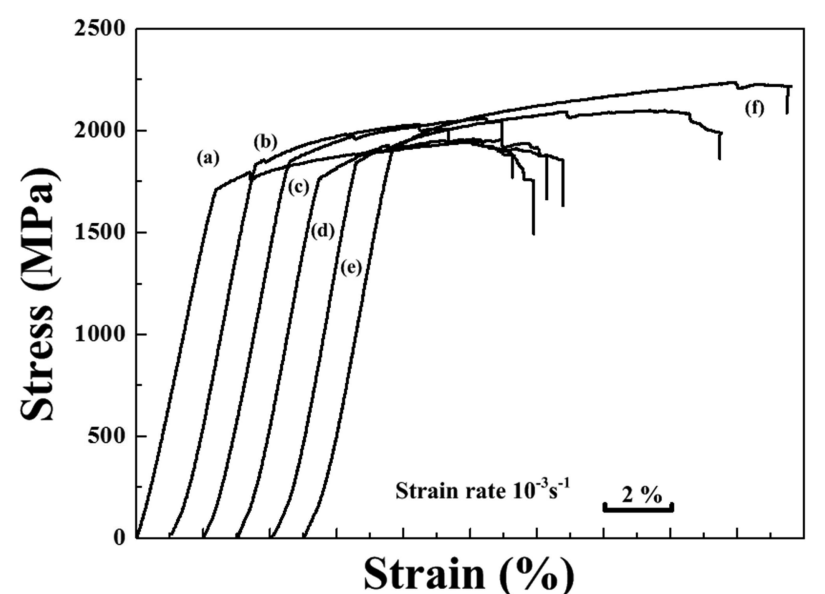

Fig. 3. Stress-strain curve of the $\left(\mathrm{Ti}_{70.5} \mathrm{Fe}_{29.5}\right)_{100-\mathrm{X}} \mathrm{Gd}_{\mathrm{X}}$ and $\left(\mathrm{Ti}_{70.5^{-}}\right.$ $\left.\mathrm{Fe}_{29.5}\right)_{100-\mathrm{X}} \mathrm{Y}_{\mathrm{X}}$ ultrafine eutectic composites with $\mathrm{X}=0.3,0.5,1.0$ at room temperature compression: (a) $\left(\mathrm{Ti}_{70.5} \mathrm{Fe}_{29.5}\right)_{99.7} \mathrm{Gd}_{0.3}$, (b) $\left(\mathrm{Ti}_{70.5^{-}}\right.$ $\left.\mathrm{Fe}_{29.5}\right)_{99.5} \mathrm{Gd}_{0.5}$, (c) $\left(\mathrm{Ti}_{70.5} \mathrm{Fe}_{29.5}\right)_{99.0} \mathrm{Gd}_{1.0}$, (d) $\left(\mathrm{Ti}_{70.5} \mathrm{Fe}_{29.5}\right)_{99.7} \mathrm{Y}_{0.3}$, (e) $\left(\mathrm{Ti}_{70.5} \mathrm{Fe}_{29.5}\right)_{99.5} \mathrm{Y}_{0.5}$ and (f) $\left(\mathrm{Ti}_{70.5} \mathrm{Fe}_{29.5}\right)_{99.0} \mathrm{Y}_{1.0}$. 
Table 2. Mechanical properties (yield stress $\sigma_{y}$, ultimate stress $\sigma_{\max }$ and plastic strain $\varepsilon_{\mathrm{p}}$ ) of the Ti-Fe-Gd and Ti-Fe-Y ultrafine eutectic composites at room temperature compression.

\begin{tabular}{ccccc}
\hline No. & Composition & $\sigma_{\mathrm{y}}(\mathrm{MPa})$ & $\sigma_{\max }(\mathrm{MPa})$ & 1954 \\
\hline (a) & $\left(\mathrm{Ti}_{70.5} \mathrm{Fe}_{29.5}\right)_{99.7} \mathrm{Gd}_{0.3}$ & 1711.18 & 2020 & 5.212 \\
(b) & $\left(\mathrm{Ti}_{70.5} \mathrm{Fe}_{29.5}\right)_{99.5} \mathrm{Gd}_{0.3}$ & 1821.06 & 2044 & 3.858 \\
(c) & $\left(\mathrm{Ti}_{70.5} \mathrm{Fe}_{29.5}\right)_{99.0} \mathrm{Gd}_{0.3}$ & 1845.32 & 1928 & 3.837 \\
(d) & $\left(\mathrm{Ti}_{70.5} \mathrm{Fe}_{29.5}\right)_{99.7} \mathrm{Gd}_{0.3}$ & 1761.44 & 2098 & 3.106 \\
(e) & $\left(\mathrm{Ti}_{70.5} \mathrm{Fe}_{29.5}\right)_{99.5} \mathrm{Gd}_{0.3}$ & 1841.16 & 2226 & 5.422 \\
(f) & $\left(\mathrm{Ti}_{70.5} \mathrm{Fe}_{29.5}\right)_{99.0} \mathrm{Gd}_{0.3}$ & 1908.06 & 5.873 \\
\hline
\end{tabular}

상온압축시험을 통하여 얻어진 $\left(\mathrm{Ti}_{70.5} \mathrm{Fe}_{29.5}\right)_{100-\mathrm{X}} \mathrm{Gd}(\mathrm{Y})_{\mathrm{X}}$ $(\mathrm{X}=0.3 \sim 1.0$ at.\%)합금 시편의 기계적 성질을 engineering stress-strain 곡선으로 정리하여 Fig. 3에 나타내었다. 기 존의 $\mathrm{Ti}_{70.5} \mathrm{Fe}_{29.5}$ 의 조성으로 이루어진 공정합금은 1800 $2000 \mathrm{MPa}$ 의 높은 항복강도를 나타내지만 국부적인 응력 집중을 견디지 못하고 소성구간 없이 급작스런 파괴를 가 져오지만, $\mathrm{Gd}$ 을 소량 첨가한 경우 $1700-1850 \mathrm{MPa}$ 의 강한 항복 강도(yield strength: $\sigma_{\mathrm{y}}$ 를 유지함을 동시에 $3 \sim 5 \%$ 의 소셩 변형률(plasticity: $\varepsilon_{\mathrm{p}}$ )을 가지고 있다. 또한 $\mathrm{TiFeY}$ 의 경우는 $\mathrm{Gd}$ 를 첨가했을 경우와 비슷하게 $1700-1900$ $\mathrm{MPa}$ 의 강한 강도와 $3-5 \%$ 의 연성을 나타냈다. $\mathrm{TiFeGd}$ 와 $\mathrm{TiFeY}$ 합금의 자세한 항복 강도 $\sigma_{\mathrm{y}}$, 최대 강도 $\sigma_{\max }$ 그리고 소성 변형률 $\varepsilon_{\mathrm{p}}$ 의 값은 Table 2 에 정리되어 있 다. $\mathrm{Gd}$ 과 $\mathrm{Y}$ 의 첨가의 양이 증가됨에 따라 항복강도는 점점 향상됨을 보이고 있으며 $\mathrm{Y}$ 의 경우에는 소성구간의 증가가 뚜렷하게 나타났다. 따라서 공정기지의 층상 조 직은 강한 강도를 유지하는 역할을 하고 초정상이나 PPT 상의 형성과 구조적 불균일성은 연성의 증가에 주요한 역할을 한 것으로 사료되어진다. 반면, $\mathrm{Gd}$ 원소를 첨가했 을 경우 $\mathrm{Ti}-\mathrm{Fe}$ 이원계 공정합금에 비해 연성의 증가를 가져왔지만, 첨가량이 증가함에 따라 소성구간이 줄어들 었음을 알 수 있었다. 이는 $\mathrm{Gd}$ 이 0.3 at.\% 첨가된 함급 의 경우 PPT상은 매우 작고 수지상 형성이 되었지만 첨 가량이 1.0 at.\%로 증가하게 되면 수지상 형성이 없고 PPT상의 크기가 조대해지며 시편 전체에 걸쳐 균일하게 분포되는 것을 알 수 있었다. 이에 따라 $\mathrm{Gd}$ 의 함량이 $0.3 \mathrm{at} \%$ 일 때 전위의 이동에 의한 Slip band의 형성이 용이한 수지상의 형성으로 인하여 더 큰 소성구간의 증 가를 가져왔다고 사료되어진다. 따라서 $\mathrm{Gd}$ 와 $\mathrm{Y}$ 원소의 첨 가에 의한 연성의 증가는 서로 다른 거동에 의한 결과 임을 예상할 수 있다. $\mathrm{Gd}$ 의 경우는 널리 알려진 석출 상 강화에 의한 기계적 물성의 향상이지만 $\mathrm{Y}$ 의 경우, 수 지상의 형성 과 구조적 불균일성이 주요한 요인이 되었 다. 이와 같이 강한 강도를 가지는 $\mathrm{TiFe}$ 공정합금에 $\mathrm{Ti}$ 와 액상분리현상을 나타내는 원소들의 소량 첨가는 공정기 지의 층상구조를 유지하면서 다른상을 형성시킴과 동시
에 구조적 불균일성도 유도할 수 있는 가능성을 보여준 다. 극미세 공정합금의 조직에 마이크론 크기의 수지상 형성이나 불균일도를 이용한 기계적 특성 향상은 이미 널리 알려져 왔다. ${ }^{13,14)}$ 하지만 첨가원소의 함량에 따라 공정기지의 조직을 유지시키는 것이 어려울 뿐 아니라 그 함량이 적으면 고용도에 의하여 관련상을 형성할 수 없었다. 하지만 열역학적인 액상분리현상을 나타내는 원 소를 첨가하는 것은 소량의 첨가에도 그 영향을 보이는 것이 가능하다. 따라서 높은 강도를 나타내는 기존의 공 정조직의 변화를 최소화 하면서 연성을 증가시키는데 효 과적인 방법이 될 수 있다. 위의 미세구조와 기계적 특 성의 결과로 보아 $\mathrm{Ti}$ 와 양의 혼합열을 가지는 $\mathrm{Gd}$ 과 $\mathrm{Y}$ 의 첨가는 응고 시 액상분리현상을 나타내어 공정기지의 변화 없이 첨가원소의 영향으로 인한 연성 증가를 보일 수 있었다.

\section{4. 결 론}

열역학 기반 선택적 미소합금화 방법을 이용하여 Ti$\mathrm{Fe}$ 극미세 공정합금 미세조직의 제어를 통하여 고강도 와 고연성을 동시에 구현하였다. 첨가원소로 $\mathrm{Ti}$ 와 액상 분리현상을 나타내는 $\mathrm{Gd}, \mathrm{Y}$ 을 선택하여 기지의 공정조 직을 유지하며 $\mathrm{Gd}$ 와 $\mathrm{Y}$ 의 상을 형성시키거나 조직의 구 조적 불균일성을 유도시켜 기계적 특성을 항상시켰다. $\beta$ $\mathrm{Ti}$ 와 $\mathrm{TiFe}$ 로 이루어진 공정기지는 전형적인 높은 강도를 나타내는데 역할을 하며, 마이크로 초정상이나 기지의 구 조적 불균일성은 연성을 증가시키는데 크게 기인하였다. 따라서 액상분리현상을 나타내는 원소의 미소합금화는 강 한 강도를 유지하며 연성을 증가시키기에 효과적이다.

\section{감사의 글}

본 연구는 2012년도 정부(교육과학기술부)의 재원으로 한국연구재단의 지원을 받아 수행한 연구임(No. 20120004996) 이에 감사드립니다. 


\section{참 고 문 헌}

1. K. S. Kumar, H. Van Swygenhoven and S. Suresh, Acta Mater., 51, 5743 (2003).

2. K. M. Youssef, R. O. Scattergood, K. L. Murty and C. C. Koch, Appl. Phys. Lett., 85, 929 (2004).

3. F. A, Mohamed and Y. Li, Mater. Sci. Eng. A, 298, 1 (2001).

4. G. He, J. Eckert, W. Löser and L. Schultz, Nat. Mater., 2, 33 (2003).

5. B. B. Sun, M. L. Sui, Y. M. Wang, G. He, J. Eckert and E. Ma, Acta Mater., 54, 1349 (2006).

6. J. M. Park, T. E. Kim, S. W. Sohn, D. H. Kim, K. B. Kim, W. T. Kim and J. Eckert, Appl. Phys. Lett., 93, 031913 (2008).

7. J. H. Han, G. A. Song, E. M. Park, S. H. Lee, J. Y. Park, Y. Seo, N. S. Lee, W. H. Lee, and K. B. Kim, Met. Mater. Int. 17(6), 873 (2011).
8. J. M. Park, D. H. Kim, K. B. Kim and W. T. Kim, Appl. Phys. Lett., 91, 131907 (2007).

9. J. Das, K.B. Kim, F. Baier, W. Löser and J. Eckert, Appl. Phys. Lett., 87, 161907 (2005).

10. J. Das, J. Eckert and R. Theissmann, Appl. Phys. Lett., 89, 261917 (2006).

11. J. H. Han, K. B. Kim, S. Yi, J. M. Park, S. W. Sohn, T. E. Kim, D. H. Kim, J. Das and J. Eckert, Appl. Phys. Lett. 93, 141901 (2008).

12. J. H. Han, K. B. Kim, S. Yi, J. M. Park, D. H. Kim, S. Pauly and J. Eckert, Appl. Phys. Lett., 93, 201906 (2008).

13. G. A. Song, J. H. Han, K. R. Lim, T. E. Kim, J. M. Park, D. H. Kim, J. Y. Park, Y. Seo and K. B. Kim, Intermetallics, 23, 27 (2012).

14. G. A. Song, J. H. Han, T. E. Kim, J. M. Park, D. H. Kim, S. Yi, Y. Seo, N. S. Lee and K. B. Kim, Intermetallics, 19(4), 536 (2011). 